\title{
Differentiation of human oligodendrocytes from pluripotent stem cells
}

\author{
Bao-Yang Hu, Zhong-Wei Du, and Su-Chun Zhang \\ Department of Anatomy and Neurology, School of Medicine and Public Health, Waisman Center, \\ WiCell Institute, University of Wisconsin-Madison, Madison, Wisconsin, USA
}

\begin{abstract}
We have developed a four-part protocol to differentiate human embryonic stem cells (hESCs) to oligodendrocyte progenitor cells (OPCs) according to developmental principles. In the first 2 weeks, hESCs are induced to differentiate into neuroepithelial cells, which form neural tube-like rosettes. In the following $10 \mathrm{~d}$, these neuroepithelial cells are specified to OLIG2-expressing progenitors in the presence of retinoic acid (RA) and sonic hedgehog (SHH). Upon treatment with fibroblast growth factor 2 (FGF2) for another $10 \mathrm{~d}$, these progenitors convert to OLIG2 and NKX2.2-expressing preOPCs. Finally, the pre-OPCs take 8-9 weeks to differentiate into OPCs, which express additional markers of oligodendrocytes, such as SOX10, platelet-derived growth factor receptor alpha (PDGFR $\alpha$ ) and NG2. The unique aspects of the protocol are the use of FGF2 to promote the differentiation of gliogenic pre-OPCs in the third part and the removal of FGF2 during the transition of pre-OPCs to OPCs. This 3-month differentiation protocol consistently yields OPCs of high purity capable of producing myelin sheaths in vivo.
\end{abstract}

\section{INTRODUCTION}

Oligodendrocytes are the glial cells that produce myelin sheaths around nerve fibers in the central nervous system. Most of the oligodendrocytes originate from neuroepithelial cells in the ventral neural tube in a sonic hedgehog (SHH)-dependent way ${ }^{1,2}$. In the spinal cord, the neural progenitors in the motor neuron progenitor ( $\mathrm{pMN}$ ) domain express OLIG2 and can give rise to either motoneurons or oligodendrocyte precursor cells (OPCs) in a time-dependent manner. During the neurogenic phase, the OLIG2 progenitors co-express neuronogenic transcription factors, such as neurogenin 2 (NGN2) and differentiate to motoneurons ${ }^{3,4}$. After this time, the OLIG2-expressing progenitors become OPCs by switching off neuronogenic transcription factors and turning on oligodendroglial transcription factors, such as NKX2.2 and SOX $10^{5-8}$. These OPCs also express platelet-derived growth factor receptor alpha $\left(\right.$ PDGFR $\alpha$ ) and the membrane proteoglycan NG2 (ref. ${ }^{9}$ ).

These developmental principles have been reproduced in vitro by differentiating mouse embryonic stem cells (ESCs) or rodent neural stem cells (NSCs) to OPCs ${ }^{10-13}$. SHH potently induces mouse ESCs to differentiate into OPCs by activating the transcriptional network described above ${ }^{11,12}$. Other soluble factors such as fibroblast growth factor 2 (FGF2) and PDGF also enhance oligodendrocyte differentiation from rodent neural stem/progenitor cells ${ }^{10,14}$. However, differentiation of human NSCs to OPCs by many laboratories over the

Correspondence should be addressed to S.-C.Z. (zhang@waisman.wisc.edu).

Reprints and permissions information is available online at http://npg.nature.com/reprintsandpermissions/.

AUTHOR CONTRIBUTIONS B.-Y.H. and Z.-W.D. designed and carried out experiments, analyzed data and wrote the paper; S.-C.Z. coordinated the study, designed experiments, analyzed data, wrote and finally approved the paper. 
past decade has not been successful ${ }^{15-17}$. Moreover, differentiation of human ESCs to OPCs is inconsistent ${ }^{18,19}$. By analyzing the transcriptional networks in response to extracellular signals during human embryonic stem cell (hESC) differentiation to OPCs, we found that human OPC specification relies on the similar SHH-dependent transcriptional network to mouse $\mathrm{ESCs}^{20}$. However, we discovered that in the human OPC differentiation process FGF2, a commonly used mitogen for neural progenitors, blocks OPC specification from NSCs by repressing hedgehog signaling ${ }^{20}$. In addition, the human OPC differentiation takes a long time in comparison to experiments with rodent cells, mainly because of the protracted period for the generation of OPCs from OLIG2 progenitors ${ }^{20}$, which nevertheless coincides with the OPC development in vivo. By incorporating these new findings, we have devised a four-part protocol for differentiating OPCs from hESCs.

\section{Overview of the protocol}

The protocol comprises the induction of neuroepithelia (or NSCs), patterning of OLIG2 progenitors, differentiation of OLIG2/NKX2.2-expressing pre-OPCs and generation of OPCs (Fig. 1). In the first part, hESCs are directed toward the neuroectoderm fate under a chemically defined condition in the absence of growth factors for 2 weeks. Neuroepithelial differentiation can be easily and reliably identified by the characteristic columnar epithelial cells that form neural tube-like rosettes ${ }^{5}$ and the expression of neuroectoderm transcription factors, including PAX6 and SOX1 $1^{21,22}$. The second part is to pattern the neuroepithelia to ventral spinal progenitors with the caudalizing factor retinoic acid (RA) and the ventralizing morphogen $\mathrm{SHH}$ in the following $10 \mathrm{~d}$. The identity of the progenitors is defined by their expression of OLIG2. These OLIG2 cells can then differentiate into spinal motoneurons. To prevent the differentiation to motoneurons and promote the generation of OPCs, we use FGF2 in the third part of the protocol for $10 \mathrm{~d}$. By day 35, the OLIG2 progenitors co-express NKX2.2 and no longer give rise to motoneurons. The co-expression of OLIG2 and NKX2.2 generally indicates the precursor of OPCs in mouse and chick ${ }^{6,8,23,24}$. However, these hESC-derived OLIG2/ NKX2.2-expressing cells do not possess morphological, biochemical and functional characteristics of OPCs. We therefore refer to these cells as pre-OPCs ${ }^{20}$. Finally, the pre-OPCs are cultured in a glia medium containing triiodothyronine (T3), neurotrophin 3 (NT3), PDGF, cAMP, IGF-1 and biotin, which individually or synergistically can promote the survival and proliferation of the hESC derived OPCs, for another 8 weeks to generate OPCs. These OPCs are bipolar or multipolar, express OLIG2, NKX2.2, SOX10 and PDGFR $\alpha$, become motile, and can further differentiate to mature oliogodendrocytes ${ }^{20}$.

\section{Applications of the protocol}

This 3-month differentiation protocol, corresponding to the developmental program of oligodendrocytes in the human spinal cord, consistently yields OPCs of high purity capable of producing myelin sheaths. It is, thus, useful to study the regulation of human oligodendrocyte development. The OPCs possess robust myelinating potential, therefore they are a potential source of cells for future clinical uses. We have also found that OPCs can be differentiated from human induced pluripotent stem cells (B.-Y.H. and S.-C.Z., unpublished observations). Hence, this protocol will allow the generation of OPCs from diseased stem cells for pathological analysis and drug screening.

\section{Limitations of the protocol}

The protracted protocol could present technical difficulty to some investigators, particularly because the mitogen FGF2 needs to be avoided during the 8-week transition period from preOPCs to OPCs. Hence, the yield of OPCs is relatively low while the purity is high. We attempted to increase the yield of OPCs by using epidermal growth factor (EGF), but this 
treatment decreased the purity of OPCs. It thus opens possibilities to explore novel ways to shorten the duration of differentiation and increase the yield without losing purity.

\section{Experimental design}

Quality of hESCs-The neuroectoderm differentiation (first part) of the protocol critically depends on the quality of hESCs, which in turn relies on the quality of the mouse embryonic fibroblast (MEF) feeder. We recommend that the MEF cells be tested with at least two hESC lines for no less than three passages. The hESCs should exhibit a uniform undifferentiated phenotype (Figs. 2a,b). Partially differentiated hESCs will decrease the neural differentiation efficiency. This protocol has been reproduced in hESC lines H1,H9 (ref. ${ }^{20}$ ) andH14 (B.-Y.H. and S.-C.Z., unpublished observations) between passages 30 and 50.

Induction of neuroepithelia-The first two parts of the protocol are similar to the protocol we described for spinal motoneuron differentiation from $\mathrm{hESCs}^{25}$, except we need to briefly disaggregate the cells before treating with FGF2, as the cells grow much faster in mediums containing FGF2. To initiate differentiation, hESCs are separated from the MEF feeder cells to form aggregates in suspension (also known as embryoid bodies). In regular cell culture vessels, the hESC aggregates usually do not attach to the bottom of the flasks/plates, and thus can be grown as spheres in suspension. The contaminating MEFs, however, will attach within $12 \mathrm{~h}$ such that the floating spheres can be removed and transferred to a new flask. The differentiation process does not require exogenous growth factors, such as FGFs and Noggin (a BMP inhibitor), as these factors are produced by the differentiating cells themselves ${ }^{26}$. In cases where hESCs are partially differentiated, addition of these factors can help the neural differentiation process.

The neuroepithelial differentiation part of the protocol takes place in adherent colony culture. After $6 \mathrm{~d}$ of floating, the hESC aggregates adhere to the laminin-coated surface to form individual flattened colonies. Such a design has two purposes, one is to allow continuous observation of morphological changes and the other is to allow the enrichment of neuroepithelial colonies by manually scraping off the non-neural colonies. The columnar epithelial cells line up radially like rosettes on day 10, which further form neural tube-like structures by days 14-17. These neural epithelial cells initially express PAX6 and then PAX6 and SOX1 (Figs. 2c-f). Thus, it takes about 2 weeks for hESCs to differentiate into neural epithelial cells.

Patterning of OLIG2 progenitors-The hESC-derived neural epithelial cells carry a dorsal anterior identity and express PAX6, OTX2 and $\mathrm{BF}^{21,22}$. For differentiation to OPCs, which originate from the ventral neural tube, it is necessary to pattern the neuroepithelia to ventral progenitors that express OLIG2. RA $(100 \mathrm{nM})$, a caudalizing factor and SHH (100 ng $\mathrm{ml}^{-1}$ ), a ventralizing morphogen, are used to pattern the cells to the ventral spinal progenitor fate from day 10 to day 21 . The identity of the progenitors is marked by OLIG2 expression. Purmorphamine, a small molecule that activates the hedgehog signaling pathway, can replace SHH in differentiating hESCs into OPCs ${ }^{20}$. Within its narrow working concentration range $(0.5-1.5 \mu \mathrm{M})$, we found $1 \mu \mathrm{M}$ of purmorphamine can efficiently direct hESCs derived NE into OLIG2 expressing progenitors ${ }^{20,27}$.

Differentiation of pre-OPCs-OLIG2-expressing progenitors appear in culture at the beginning of the fourth week of culture, and most of these cells become motorneurons within the next $10 \mathrm{~d}$ (day 25 through 35) following our protocol for motoneuron differentiation ${ }^{25}$. We discovered that during this period, removal of RA and addition of FGF2 $\left(10 \mathrm{ng} \mathrm{ml}^{-1}\right)$ almost completely blocks the OLIG2-expressing cells from differentiating into motoneurons ${ }^{20}$. We dissociate the cell aggregates at day 23 so that on day 24 individual cells re-aggregate into 
clusters, at which size FGF2 can easily diffuse through. FGF2 promotes proliferation of the neural progenitors so that there is no obvious change in cell morphology during this period. We normally change $1 / 3$ to $1 / 2$ of the culture medium, so that the culture environment is not drastically altered during each feeding. When culture condition changes from the previous steps (e.g., factors are removed from or added to the culture medium), we usually pellet the cells by a brief centrifugation step, followed by replacing the old medium with the same amount of fresh medium but with a new recipe. In the steps following FGF2 removal, cAMP, PDGFAA, IGF and NT3 are supplemented in the culture to allow for better survival of the pre-OPCs or OPCs. In addition, biotin in the medium can fulfill the increasing demands of the oligodendrocyte lineage for synthesizing lipids.

Consequently, the populations of OLIG2-expressing cells, which now also express NKX2.2, increase significantly by day 35 . It should be noted that only the OLIG2 and NKX2.2 double positive cells can give rise to OPCs. Hence, cells that co-express OLIG2 and NKX2.2 should be quantified by either counting or FACS analysis ${ }^{20}$. Different from those in rodents and birds, the hESC derived OLIG2 NKX2.2-expressing cells do not express other markers of OPCs. Thus, we refer to these cells as pre-OPCs (Figs. 3a,b).

Generation of OPCs-Transition from pre-OPCs to OPCs is a protracted step, taking about 8-9 weeks. This process is still SHH-dependent, as inhibition of hedgehog signaling blocks OPC differentiation. Nevertheless, addition of exogenous SHH does not significantly increase the yield of OPCs. Thus, we do not continue using SHH or purmorphamine after day 50 of differentiation. We attempted to speed up the process by adding growth factors known to enhance oligodendrogliogenesis in other vertebrates (e.g., SHH, neuregulin, for proliferation or PDGF-AA, NT3 and IGF for survival), or by removing differentiation factors such as T3 or blocking FGF signaling. However, none of these treatments altered the timing of the differentiation process. Another unique aspect of this part of the protocol is that the expansion of progenitors with media containing FGF2 will block OPC generation. Hence, we culture the pre-OPCs in suspension for the next several weeks without mitogens. The suspension culture helps in preventing the progenitors from differentiating into neurons or astrocytes before they are specified to OPCs. During this process, the progenitors do not proliferate substantially. However, over the long period of culture, the large clusters need to be regularly disaggregated to smaller ones, so that the cells inside the clusters can be better nourished. Another mitogen, EGF $\left(10 \mathrm{ng} \mathrm{ml}^{-1}\right)$ can promote the proliferation of the pre-OPCs. However, the proportion of OPCs decreases after expansion of pre-OPCs in the presence of EGF, thus we exclude it.

Oligodendrocyte progenitor cells can be identified by their characteristic bipolar morphology on laminin or ornithine substrates (Fig. 3c). These substrates are ideal for motile OPCs to migrate and extend processes. The OPC clusters may be dissociated into individual cells or plated as clusters; the latter is technically easier and allows measurement of the distance the cells have migrated. To confirm the identity of OPCs, we stain them for the transcription factor SOX10 in addition to OLIG2 and NKX2.2, and the cell surface markers PDGFR $\alpha$ and NG2 (Fig. 3d). The co-expression of OLIG2 and NKX2.2, which is used to define OPCs in other vertebrates, is not sufficient for marking OPCs, as described above. A bona fide human OPC should express all of these markers simultaneously. The OPCs begin to appear during the tenth week of differentiation, but in a small number $(<3 \%)$. The population increases gradually in the next 3 weeks, but bursts in the fourteenth week, reaching $80 \%$ in the total population. This time course is likely related to the intrinsic program of human oligodendrocyte development although the exact mechanism is unknown.

Further differentiation of OPCs results in branching of the process, exhibiting extensively ramified processes like a spider web (Fig. 3e). The oligodendrocyte identity can be marked by a surface antibody called O4, which specifically labels maturing oligodendrocytes ${ }^{28}$ (Fig. 3f). 
For some membrane proteins, such as O4, NG2 and PDGFR $\alpha$, we usually incubate live cells with antibodies against these proteins before the cells are fixed ${ }^{20}$. Staining after regular fixation, which permeabilizes the cells, will give non-continuous membrane staining. Under the serum-free culture condition and in the absence of neurons (neurites), the majority of $\mathrm{O} 4$ + immature oligodendrocytes fail to mature and produce myelin sheathes around nerve fibers, and hence usually do not survive for a long period. Consequently, the $\mathrm{O} 4+$ proportion is usually around $40 \%$ of the total population. As PDGF, IGF and NT3 $\left(10 \mathrm{ngml}^{-1}\right)$ do not promote the $\mathrm{O} 4+$ oligodendrocytes to proliferate at this stage, only moderate amounts $\left(5 \mathrm{ng} \mathrm{ml}^{-1}\right)$ of these components are supplemented for a better survival of the cells. A small number of oligodendrocytes, which do survive under such a condition, will mature and express myelin basic protein (MBP), which is required for producing compact myelin sheath. The functional identity of the hESC-derived OPCs can be best confirmed by their ability to migrate, mature and produce myelin sheaths around axons after transplantation into the brain of the dysmyelinating shiverer mice ${ }^{20}$.

\section{MATERIALS}

\section{REAGENTS}

- ACCUTASE (Innovative Cell Technology, cat. no. AT 104)

- B27 supplement without vitamin A 50× (Gibco-BRL, cat. no. 12587-010)

- Brain derived neurotrophic factor (BDNF, PeproTech, cat. no. 450-02)

- $\quad \beta$-Mercaptoethanol (14.3 M) (Sigma, cat. no. M7522)! CAUTION Combustible, corrosive and toxic if ingested and absorbed through the skin. Avoid direct contact or exposure to ignition sources.

- Fibroblast growth factor 2 (FGF2, R\&D, cat. no. 233-FB)

- Biotin (Sigma, cat no. B4639)

- Bovine serum albumin (BSA) (Sigma, cat. no. A-7906)

- Cyclic AMP (Sigma, cat. no. D-0260)

- Dispase (Gibco-BRL, cat. no. 17105-041)

- Dulbecco's modified Eagle's medium:Nutrient mixture F-12 1:1 (DMEM: F-12, Gibco-BRL, cat. no. 11330)

- Heparin (Sigma, cat. no. H3149)

- Insulin-like growth factor 1 (IGF1, PeproTech, cat. no. 100-11)

- Knockout serum replacer (Gibco-BRL, cat. no. 10828) $\mathbf{A}$ CRITICAL Store stock at $-80{ }^{\circ} \mathrm{C}$. Make aliquots of $50 \mathrm{ml}$ and store at $-20{ }^{\circ} \mathrm{C}$ if the whole stock cannot be used within a week of thawing.

- Leibovitz's L-15 Medium (Gibco-BRL, cat. no. 11415)

- L-Glutamine solution (Gibco-BRL, cat. no. 25030)

- Laminin from human placenta (Sigma, cat. no. L6274)

- MEM non-essential amino acids solution (Gibco-BRL, cat. no. 11140)

- $\quad$ N1 supplement $100 \times$ (Sigma)

- $\quad \mathrm{N} 2$ supplement $100 \times$ (Gibco-BRL, cat. no. 17502-048) 
- Paraformaldehyde (PFA, Sigma-Aldrich, cat. no. P6148)! CAUTION Toxic if inhaled. Harmful if absorbed through skin and may cause skin irritation. Use PFA in a fume hood and avoid contact with skin and eyes.

- Platelet-derived growth factor (PDGF-AA, R\&D, cat. no. 221-AA)

- $\quad$ Poly-L-ornithine (Sigma, cat. no. P3655)

- Purmorphamine (Calbiochem, cat. no. 540220)

- Retinoic acid (Sigma, cat. no. R2625)

- Sonic hedgehog (SHH, R\&D, cat. no. 1845-SH)

- Antibodies (see Table 1)

\section{EQUIPMENT}

- $\quad$ 15-ml and 50-ml conical tubes (BD Biosciences, cat. no. 352095 and 352073)

- 30-mm Petri dishes (Fisher Scientific, cat. no. 08-757-13A)

- 6-well and 24-well plates (Nunc, cat. no. 140675 and 142475)

- 9" Pasteur pipettes (Fisher Scientific, cat. no. 13-678-20D)

- Cover slips (diameter 12 mm, Bellco Glass, cat. no. 1943-10012)

- Micropipette puller (model 720, David KOPF instrument)

- Laboratory plastic tubing $(0.02-0.04$ ". inner diameter)

- Stericup filtration system (Millipore, cat. no. SCGPU05RE).

- Steriflip filtration system (Millipore, cat. no. SCGP00525)

- T25 and T75 flasks (Nunc, cat. no. 136196 and 178891)

- Desktop centrifuge (Centrifuge 5702, Eppendorf)

\section{REAGENT SETUP}

Human ESC growth medium $(\mathbf{5 0 0} \mathbf{~ m l})$ - Under sterile conditions combine $392.5 \mathrm{ml}$ of DMEM:F-12,100 ml of Knockout serum replacer, $5 \mathrm{ml}$ of MEM non-essential amino acids solution, $2.5 \mathrm{ml}$ of $200 \mathrm{mM} \mathrm{L}$-glutamine solution (final concentration of $1 \mathrm{mM}$ ) and $3.5 \mu \mathrm{l}$ of 14.3 M $\beta$-mercaptoethanol (final concentration of $0.1 \mathrm{mM}$ ). The medium can be stored at $4^{\circ}$ $\mathrm{C}$ for up to 7-10 d.! CAUTION $\beta$-Mercaptoethanol is combustible, corrosive and toxic if ingested and absorbed through the skin. Avoid ingestion, direct contact or direct exposure to ignition.

Neural differentiation medium (DMEM:F-12/N2, $500 \mathrm{ml}$ )—Under sterile conditions combine $489 \mathrm{ml}$ of DMEM:F-12, $5 \mathrm{ml}$ of $\mathrm{N} 2$ supplement, $5 \mathrm{ml}$ of MEM non-essential amino acids solution and $1 \mathrm{ml}$ of $1 \mathrm{mg} \mathrm{ml}^{-1}$ heparin. The medium can be stored at $4{ }^{\circ} \mathrm{C}$ for up to 2 weeks.

Glia differentiation medium-Under sterile conditions combine $479 \mathrm{ml}$ of DMEM:F-12, $5 \mathrm{ml}$ of $\mathrm{N} 1$ supplement, $10 \mathrm{ml}$ of B27 supplement, $5 \mathrm{ml}$ of MEM non-essential amino acids solution, $0.3 \mathrm{ml}$ of $100 \mathrm{mg} \mathrm{ml}^{-1} \mathrm{~T} 3,0.5 \mathrm{ml}$ of $1 \mathrm{mM} \mathrm{cAMP}$ and $50 \mu \mathrm{l}$ of $1 \mathrm{mg} \mathrm{ml}^{-1}$ biotin. The medium can be stored at $4{ }^{\circ} \mathrm{C}$ for up to 2 weeks. 
Dispase (1 $\mathrm{U} \mathrm{ml}^{-1}$ )—Dissolve $50 \mathrm{U}$ dispase in $50 \mathrm{ml}$ of DMEM:F-12. Warm at $37^{\circ} \mathrm{C}$ for $15 \mathrm{~min}$. Dissolve it completely and filter with a $50 \mathrm{ml}$ Steri-flip. Can be stored at $4{ }^{\circ} \mathrm{C}$ for up to 2 weeks. $\triangle$ CRITICAL Be aware that the amount of $50 \mathrm{U}$ dispase varies between lots.

Heparin (1 mgml $\left.{ }^{-1}\right)$-Dissolve $1 \mathrm{mg}$ of heparin in $10 \mathrm{ml}$ DMEM medium, aliquot and store at $-80{ }^{\circ} \mathrm{C}$ for up to 3 months.

FGF2 (100 $\mathbf{~ g ~ m ~}^{-1}$ )—Dissolve $100 \mu \mathrm{g}$ of bFGF in $1 \mathrm{ml}$ of sterilized PBS with $0.1 \%$ (wt/ vol) $\mathrm{BSA}$, aliquot and store at $-80{ }^{\circ} \mathrm{C}$ for up to 3 months.

IGF-1, PDGF-AA (100 $\left.\mathbf{~ g ~ m l}^{-1}\right)$-Dissolve $100 \mu \mathrm{g}$ of growth factor in $1 \mathrm{ml}$ sterilized distilled water or PBS with $0.1 \%$ (wt/vol) BSA, aliquot and store at $-80^{\circ} \mathrm{C}$ for up to 3 months.

SHH (100 $\left.\mathbf{~ g ~ m l}^{-1}\right)$-Dissolve $100 \mu \mathrm{g}$ of SHH in $1 \mathrm{ml}$ of sterilized PBS with $0.1 \%$ (wt/vol) BSA. Aliquot $100 \mu \mathrm{l}$ into sterilized tubes and store at $-80^{\circ} \mathrm{C}$ for up to 3 months.

Purmorphamine (10 $\mathbf{~ m M ) - D i s s o l v e ~} 5 \mathrm{mg}$ of purmorphamine in $480 \mu \mathrm{l}$ ethanol and 480 $\mu \mathrm{l}$ DMSO, aliquot and store at $-20{ }^{\circ} \mathrm{C}$ for up to 8 weeks. $\triangle$ CRITICAL The working concentration range of purmorphamine is very narrow. Prepare the stock solution as accurately as possible. When adding stock solution into the culture medium, use the smallest tip and at well-calibrated pipetteman.

RA (100 mM)—Dissolve $50 \mathrm{mg}$ of RA in $1.67 \mathrm{ml}$ of DMSO. Aliquot $50 \mu \mathrm{l}$ into brown microtubes and store at $-80^{\circ} \mathrm{C}$. $\triangle$ CRITICAL RA is extremely sensitive to UV light, air and oxidizing agents, especially in solution. It is recommended to use all the powder immediately after opening the ampoule. Dilute each aliquot with $4.95 \mathrm{ml}$ ethanol and store at $-20{ }^{\circ} \mathrm{C}$ as a working stock solution. Try not to use working stock solution older than 2 weeks.

Cyclic AMP (1 mM)—Dissolve $4.914 \mathrm{mg}$ of cyclic AMP in $10 \mathrm{ml}$ of sterilized water. Aliquot and store at $-80{ }^{\circ} \mathrm{C}$ for up to 3 months.

Biotin (1 $\mathrm{mg} \mathrm{ml}^{-1}$ )—Disolve $100 \mathrm{mg}$ of biotin in $10 \mathrm{ml}$ of $1 \mathrm{~N} \mathrm{NaOH}$, aliquot in $1 \mathrm{ml}$ each and store at $-80^{\circ}$ for up to 6 months. Dilute $1 \mathrm{ml}$ of concentrated stock solution in $10 \mathrm{ml}$ of DMEM:F-12 and filter through a $0.22 \mu \mathrm{m}$ teflon filter, store at $4{ }^{\circ} \mathrm{C}$ for up to 4 weeks.

Boric acid buffer (pH 8.4)—In $100 \mathrm{ml}$ of distilled water add $0.927 \mathrm{~g} \mathrm{H}_{3} \mathrm{BO}_{3}$ and $0.6 \mathrm{~g}$ $\mathrm{NaOH}$. Adjust $\mathrm{pH}$ to 8.4 by adding $\mathrm{HCl}$. Store at room temperature $\left(20-25^{\circ} \mathrm{C}\right)$ for up to 3 months.

10x Poly-L-ornithine (1 $\mathrm{mg} \mathrm{ml}^{-1}$ )—Add $0.1 \mathrm{~g}$ of poly-L-ornithine to $100 \mathrm{ml}$ of boric acid buffer $\mathrm{pH}$ 8.4. Filter through a $0.22 \mu \mathrm{m}$ teflon filter. Store at room temperature $\left(20-25^{\circ} \mathrm{C}\right)$ for up to 3 months.

4\% PFA (wt/vol) (100 ml) - In a fume hood add $4 \mathrm{~g}$ of PFA with a stirring bar to the water. Keep stirring while heating up to $60^{\circ} \mathrm{C}$. Add $1-2$ drops of $2 \mathrm{~N} \mathrm{NaOH}$ until the solution becomes clear. Let the solution cool down to room temperature. In a separate beaker slowly add $0.22 \mathrm{~g}$ of sodium phosphate monobasic and $1.22 \mathrm{~g}$ of sodium phosphate dibasic into $30 \mathrm{ml}$ of water and stir to help to dissolve them. Mix the sodium phosphate buffer and PFA solutions and adjust the $\mathrm{pH}$ of the solution to 7.2-7.4 with $\mathrm{HCl}$. Add water to $100 \mathrm{ml}$ and filter. Store at $4^{\circ}$ $\mathrm{C}$ and use the fixative within a week. ! CAUTION Toxic if inhaled. Harmful if absorbed through skin and may cause skin irritation. Avoid contact with skin and eyes. $\triangle$ CRITICAL Be careful not to overheat the PFA solution. 
Antibodies Refer to Table 1 for details.

\section{EQUIPMENT SETUP}

Poly-L-ornithine coated coverslips-In a sterile hood, put one sterilized coverslip in each well of a 24-well plate. Add $75 \mu \mathrm{l}$ of $0.1 \mathrm{mg} \mathrm{ml}^{-1}$ poly-L-ornithine onto each coverslip. Incubate the plates at $37{ }^{\circ} \mathrm{C}$ overnight. The next day, aspirate poly-L-ornithine and let the coverslips dry for $\sim 30 \mathrm{~min}$. Wash three times with $1 \mathrm{ml}$ of sterile water for each well. Leave the plate open in the hood until the coverslips dry completely. Cover the plates, wrap in foil and label with the date. Plates can be stored at $-20{ }^{\circ} \mathrm{C}$ for 2 weeks.

Laminin coated 6-well plate-Dilute laminin with fresh neural differentiation medium to a final concentration of $20 \mu \mathrm{g} \mathrm{ml}^{-1}$. Add $300 \mu \mathrm{l}$ of laminin solution into each well of a 6-well plate. Let the medium hold as a big drop and spread within the central area of the well. Do not let the medium drain to the edge. Incubate the plate at $37{ }^{\circ} \mathrm{C}$ for $1 \mathrm{~h}$. Prepare the plates for prompt use only. $\triangle$ CRITICAL Laminin is very easily absorbed by plastic and tends to form aggregates at room temperature. Store laminin at $-80^{\circ} \mathrm{C}$ and thaw at $4{ }^{\circ} \mathrm{C}$ before using. Do not aliquot laminin to plastic tubes from the original glass vial.

\section{PROCEDURE}

\section{Induction of primitive neuroepithelial cells • TIMING $10 \mathrm{~d}$ (days $\mathbf{0 - 1 0}$ )}

1. Induce the primitive neuroepithelial cells according to Steps 1-26 of our protocol for motoneuron differentiation from $\mathrm{hESCs}^{25}$.

\section{Specification of Olig2-expressing progenitors • TIMING $15 \mathrm{~d}$ (days 10-25)}

2. Differentiate OLIG2-expressing progenitors following Steps 27-39 of our motor neuron protocol ${ }^{25}$. Cells from 1 to 2 6-well plates should be cultured in one T- 75 flask in $35 \mathrm{ml}$ of neural differentiation medium containing B27, $0.1 \mu \mathrm{M}$ of RA and $100 \mathrm{ng} \mathrm{ml}^{-1} \mathrm{SHH}$ (or purmorphamine at $1 \mu \mathrm{M}$ ).

3. On day 21 feed the cells one more time as described in Step 39 of our previous protocol ${ }^{25}$. On day 23 , stand the flask for 3 min so that clusters larger than $200 \mu \mathrm{m}$ will settle down to the bottom and the small clusters remain in suspension. Disaggregate the larger clusters using ACCUTASE or a glass pipette as described in Step 40 of our protocol of motoneuron differentiation from $\mathrm{hESC}^{25}$. Transfer the smaller clusters that remained in suspension into a $50 \mathrm{ml}$ conical tube. Centrifuge the tube at $80 \mathrm{~g}$ for $2 \mathrm{~min}$, room temperature. Remove the old medium and re-suspend the pellet with $5 \mathrm{ml}$ of the neural differentiation medium described in Step 2.

4. Collect all the cells and transfer into a T-75 flask and incubate at $37{ }^{\circ} \mathrm{C}, 5 \% \mathrm{CO}_{2}$ in a total of $35 \mathrm{ml}$ of the fresh neural differentiation medium described in Step 2.

5. On day 24, follow the procedures described in Box 1 of our motoneuron differentiation protocol $^{25}$ to plate $4-5$ clusters of cells (about $100 \mu \mathrm{m}$ in diameter measured with an objective ruler on the microscope) onto poly-L-ornithine and laminin coated coverslips in $50 \mu \mathrm{l}$ of neural differentiation medium described in Step 2. Immunostain the attached clusters for OLIG $2^{20}$.

\section{Generation of pre-OPCs • TIMING $10 \mathrm{~d}$ (days 25-35)}

6. On day 25 , collect the cells from Step 4 into a $50 \mathrm{ml}$ conical tube and let the cells settle down for $5 \mathrm{~min}$. Remove most of the old medium but leave $2-3 \mathrm{ml}$ in the tube so that the cell clusters will not be accidentally sucked out. Resuspend the cell clusters with $35 \mathrm{ml}$ of the neural differentiation medium described in Step 2, except replacing RA with FGF2 at 
a final $\boldsymbol{\Delta}$ concentration of $10 \mathrm{ng} \mathrm{ml}^{-1}$. Culture the cells in an incubator at $37{ }^{\circ} \mathrm{C}, 5 \%$ $\mathrm{CO}_{2}$.

$\triangle$ CRITICAL STEP Remember to replace RA with FGF2 from this step onwards.

7. On days 27, 29, 31 and 33, stand the flask at a angle of 45 degree to collect the cells to one corner, remove half (about $20 \mathrm{ml}$ ) of the medium and replenish with the neural differentiation medium described in Step 6. Culture the cells in an incubator at $37^{\circ} \mathrm{C}, 5 \%$ $\mathrm{CO}_{2}$.

8. On days 34-35, plate 4-5 clusters of cells, usually 150-200 $\mu \mathrm{m}$ in diameter, onto polyL-ornithine and laminin coated coverslips as described in Box 1 of our protocol for motoneuron differentiation from hESCs (ref. ${ }^{25}$ ). Once the cells have attached, double stain the cells for OLIG2 and NKX2.2 (ref. ${ }^{20}$ ).

\section{Transition from pre-OPCs to OPCs in suspension • TIMING $49 \mathrm{~d}$ (days 35-84)}

9. On day 35 (fifth week), settle down the clusters from Step 7 and remove the medium as described in Step 6. Resuspend the cells with $35 \mathrm{ml}$ of glia differentiation medium (DMEM/F12, $1 \mathrm{X} \mathrm{Nl}$ supplement, $1 \mu \mathrm{M}$ purmorphamine, $60 \mathrm{ng} \mathrm{ml}^{-1} \mathrm{~T} 3,100 \mathrm{ng} \mathrm{ml}^{-1}$ biotin and $1 \mu \mathrm{M}$ cAMP), supplemented with an additional cocktail of cytokines and growth factors consisting of PDGF-AA, IGF1 and NT3 (all at $10 \mathrm{ng} \mathrm{ml}^{-1}$ ). Culture the cells in an incubator at $37{ }^{\circ} \mathrm{C}, 5 \% \mathrm{CO}_{2}$. Culture the cells for 2 weeks. $\triangle$ CRITICAL STEP FGF2 is removed from the medium at this step.

10. On days 38, 41, 44 and 47, settle down the clusters using the procedure described in Step 7. Change half of the medium and replenish with the medium described in Step 9.

11. On day 49 (seventh week), disaggregate the big progenitor spheres into smaller cell clusters using the same procedures described in Step 40 of our previous protocol ${ }^{25}$. Transfer the disaggregated cells into a T-75 flask in $35 \mathrm{ml}$ of the glia differentiation medium described in Step 9, except that purmorphamine is no longer needed from this step on.

$\triangle$ CRITICAL STEP Purmorphamine is not needed from this step on.

12. Continue feeding the cells as described in Step 10 but ensure that purmorphamine is removed from the medium.

13. On day 70 (tenth week), disaggregate the big clusters one more time using the procedures described in Step 40 of our previous protocol ${ }^{25}$.

$\triangle$ CRITICAL STEP Briefly disaggregate the cells to loosen clusters, but do not let the cells dissociate to single cells.

14. Culture the cells in a T-75 flask and in $35 \mathrm{ml}$ of the glia differentiation medium described in Step 11, let the cells aggregate for $3 \mathrm{~d}$.

15. On day 73, stand the flask and let the cell clusters sink down to the bottom as described in Step 7. Remove most of the medium containing dead cells and debris leaving the last 2-3 $\mathrm{ml}$ behind. Feed the cell clusters with $35 \mathrm{ml}$ of the glia differentiation medium described in Step 11.

16. On days 77 and 82, feed the floating cell clusters using the same procedures as described in Step 7, but with the glia differentiation medium described in Step 11.

\section{Differentiate OPCs on substrate • TIMING 48 d (days 84-112)}

17. On day 84 (twelfth week), transfer about 50 clusters of cells into a $60-\mathrm{mm}$ petri-dish in $5 \mathrm{ml}$ of the glia differentiation medium described in Step 11. Continue culturing the 
remaining clusters in suspension in $35 \mathrm{ml}$ of the same medium in a T-75 flask. Feed the cells twice a week as described in Step 7. These cells can be used for additional maturation and functional analysis, or for transplantation within the next 4 weeks (ref. ${ }^{20}$ ).

18. Pick up 4-5 clusters of cells from the petri-dish and plate them onto glass coverslips that are coated with poly-ornithine and laminin in $50 \mu \mathrm{l}$ of the glia differentiation medium.

\section{? TROUBLESHOOTING}

19. Incubate the cells at $37{ }^{\circ} \mathrm{C}, 5 \% \mathrm{CO}_{2}$ overnight. The next day, feed the cells with 0.5 $\mathrm{ml}$ of glia differentiation medium supplemented with PDGF-AA, IGF1 and NT3, all at 5 $\mathrm{ng} \mathrm{ml}{ }^{-1}$.

\section{? TROUBLESHOOTING}

20. After $24 \mathrm{~h}$ of culture (day 85), check the culture and observe the bi-polar or multipolar OPCs migrating out from the clusters.

21 . Feed the cells every other day by removing $0.3-0.4 \mathrm{ml}$ of the old medium and adding back the same volume of the fresh glia differentiation medium described in Step 19 for the next $10 \mathrm{~d}$.

$\triangle$ CRITICAL STEP Feed the cells with $2 / 3$ fresh medium in order not to disturb the attached cells.

22. On day 98 (fourteenth week), immunostain the cells for OLIG2, NKX2.2, SOX10, PDGFR $\alpha$ and NG2 (ref. ${ }^{20}$ ). Refer to Table 1.

\section{? TROUBLESHOOTING}

23. On day 112 (sixteenth week), immunostain the cells with 04 antibodies ${ }^{20}$.

\section{? TROUBLESHOOTING}

- TIMING

Step 1, induction of primitive neuroepithelial cells: $10 \mathrm{~d}$

Steps $2-5$, specification of Olig2-expressing progenitors: $15 \mathrm{~d}$

Steps 6-8, generation of pre-OPCs: $10 \mathrm{~d}$

Steps 9-16, transition from pre-OPCs to OPCs in suspension: $49 \mathrm{~d}$

Steps 17-23, differentiation of oligodendrocytes on substrate: $48 \mathrm{~d}$

\section{? TROUBLESHOOTING}

Troubleshooting advice can be found in Table 2 .

\section{ANTICIPATED RESULTS}

The four-part OPC differentiation from hESCs mirrors in vivo development of the neural plate/ tube (induction of neuro-epithelia), patterning of the pMN domain in the ventral neural tube (specification of OLIG2 progenitors), differentiation of pre-OPCs (differentiation of OLIG2/ NKX2.2-expressing progenitors), and generation of OPCs (Fig. 1). In the first part, which takes 10-14 d (Steps 1-26 (ref. $\left.{ }^{25}\right)$ ), we expect that at least 90-95\% of the differentiated progenies will be PAX6 positive neuroepithelial cells (Fig. 2) ${ }^{21}, 22$. In the second part, the combination of RA and SHH will induce about $60 \%$ of the progenitors to be OLIG2 positive ventral progenitors. When SHH is replaced with purmorphamine, we expect a higher proportion of OLIG2 progenitors, up to $80 \%$. By using FGF2 and SHH on the floating cell spheres in the third part, we predict that $\sim 40 \%$ of the OLIG2 cells also express NKX2.2, indicative of pre- 
OPCs (Figs. 3a,b). The last part of the protocol is very long and requires the avoidance of FGF2. Hence, there is limited cell expansion even though the cells continue to divide. By the end of the fourteenth week, the PDGFR $\alpha+$ cells will account for $\sim 80 \%$ of the total population and most cells co-express OLIG2, NKX2.2, SOX10 or NG2 (Figs. 3c,d). Further differentiation of the OPCs will result in maturation of the progenitors, as indicated by 04 in immature oligodendrocytes (Figs. 3e,f) and MBP in mature oligodendrocytes ${ }^{20}$. After transplantation into the brain of shiverer mice, the hESC derived OPCs usually migrate in the corpus callosum. These cells express MBP and form myelin sheaths around nerve fibers ${ }^{20}$.

\section{Acknowledgments}

This study was supported by the National Institute of Neurological Disorders and Stroke (R01 NS045926), the National Multiple Sclerosis Society (NMSS TR-3761), a gift from the Busta family and the Bleser family, and partly by a core grant to the Waisman Center from the National Institute of Child Health and Human Development (P30 HD03352).

\section{References}

1. Lu QR, et al. Sonic hedgehog-regulated oligodendrocyte lineage genes encoding bHLH proteins in the mammalian central nervous system. Neuron 2000;25:317-329. [PubMed: 10719888]

2. Zhou Q, Wang S, Anderson DJ. Identification of a novel family of oligodendrocyte lineage-specific basic helix-loop-helix transcription factors. Neuron 2000;25:331-343. [PubMed: 10719889]

3. Sugimori M, et al. Combinatorial actions of patterning and HLH transcription factors in the spatiotemporal control of neurogenesis and gliogenesis in the developing spinal cord. Development 2007;134:1617-1629. [PubMed: 17344230]

4. Lee SK, Lee B, Ruiz EC, Pfaff SL. Olig2 and Ngn2 function in opposition to modulate gene expression in motor neuron progenitor cells. Genes Dev 2005;19:282-294. [PubMed: 15655114]

5. Marquardt T, Pfaff SL. Cracking the transcriptional code for cell specification in the neural tube. Cell 2001;106:651-654. [PubMed: 11572771]

6. Qi Y, et al. Control of oligodendrocyte differentiation by the $\mathrm{Nkx} 2.2$ homeodomain transcription factor. Development 2001;128:2723-2733. [PubMed: 11526078]

7. Stolt CC, Lommes P, Friedrich RP, Wegner M. Transcription factors Sox 8 and Sox 10 perform nonequivalent roles during oligodendrocyte development despite functional redundancy. Development 2004;131:2349-2358. [PubMed: 15102707]

8. Zhou Q, Choi G, Anderson DJ. The bHLH transcription factor Olig2 promotes oligodendrocyte differentiation in collaboration with Nkx2.2. Neuron 2001;31:791-807. [PubMed: 11567617]

9. Zhang SC. Defining glial cells during CNS development. Nat Rev Neurosci 2001;2:840-843. [PubMed: 11715061]

10. Avellana-Adalid V, Nait-Oumesmar B, Lachapelle F, Baron-Van Evercooren A. Expansion of rat oligodendrocyte progenitors into proliferative "oligospheres" that retain differentiation potential. J Neurosci Res 1996;45:558-570. [PubMed: 8875321]

11. Billon N, Jolicoeur C, Ying QL, Smith A, Raff M. Normal timing of oligodendrocyte development from genetically engineered, lineage-selectable mouse ES cells. J Cell Sci 2002;115:3657-3665. [PubMed: 12186951]

12. Du ZW, Li XJ, Nguyen GD, Zhang SC. Induced expression of Olig2 is sufficient for oligodendrocyte specification but not for motoneuron specification and astrocyte repression. Mol Cell Neurosci 2006;33:371-380. [PubMed: 17035043]

13. Samanta J, Kessler JA. Interactions between ID and OLIG proteins mediate the inhibitory effects of BMP4 on oligodendroglial differentiation. Development 2004;131:4131-4142. [PubMed: 15280210]

14. Zhang SC, Lundberg C, Lipsitz D, O'Connor LT, Duncan ID. Generation of oligodendroglial progenitors from neural stem cells. J Neurocytol 1998;27:475-489. [PubMed: 11246488]

15. Chandran S, et al. FGF-dependent generation of oligodendrocytes by a hedgehog-independent pathway. Development 2003;130:6599-6609. [PubMed: 14660548] 
16. Roy NS, et al. Identification, isolation, and promoter-defined separation of mitotic oligodendrocyte progenitor cells from the adult human subcortical white matter. J Neurosci 1999;19:9986-9995. [PubMed: 10559406]

17. Zhang SC, Ge B, Duncan ID. Tracing human oligodendroglial development in vitro. J Neurosci Res 2000;59:421-429. [PubMed: 10679779]

18. Izrael M, et al. Human oligodendrocytes derived from embryonic stem cells: effect of noggin on phenotypic differentiation in vitro and on myelination in vivo. Mol Cell Neurosci 2007;34:310-323. [PubMed: 17196394]

19. Kang SM, et al. Efficient induction of oligodendrocytes from human embryonic stem cells. Stem Cells 2007;25:419-424. [PubMed: 17053214]

20. Hu BY, Du ZW, Li XJ, Ayala M, Zhang SC. Human oligo dendrocytes from embryonic stem cells: conserved SHH signaling networks and divergent FGF effects. Development 2009;136:1443-1452. [PubMed: 19363151]

21. Li XJ, et al. Specification of motoneurons from human embryonic stem cells. Nat Biotechnol 2005;23:215-221. [PubMed: 15685164]

22. Pankratz MT, et al. Directed neural differentiation of human embryonic stem cells via an obligated primitive anterior stage. Stem Cells 2007;25:1511-1520. [PubMed: 17332508]

23. Fu H, et al. Dual origin of spinal oligodendrocyte progenitors and evidence for the cooperative role of Olig2 and Nkx2.2 in the control of oligodendrocyte differentiation. Development 2002;129:681693. [PubMed: 11830569]

24. Vallstedt A, Klos JM, Ericson J. Multiple dorsoventral origins of oligodendrocyte generation in the spinal cord and hindbrain. Neuron 2005;45:55-67. [PubMed: 15629702]

25. Hu BY, Zhang SC. Differentiation of spinal motor neurons from pluripotent human stem cells. Nat Protoc 2009;4:1295-1304. [PubMed: 19696748]

26. Lavaute TM, et al. Regulation of neural specification from human embryonic stem cells by BMP and FGF. Stem Cells 2009;27:1741-1749. [PubMed: 19544434]

27. Li XJ, et al. Directed differentiation of ventral spinal progenitors and motor neurons from human embryonic stem cells by small molecules. Stem Cells 2008;26:886-893. [PubMed: 18238853]

28. Sommer I, Schachner M. Monoclonal antibodies (01 to 04$)$ to oligodendrocyte cell surfaces: an immunocytological study in the central nervous system. Dev Biol 1981;83:311-327. [PubMed: 6786942] 


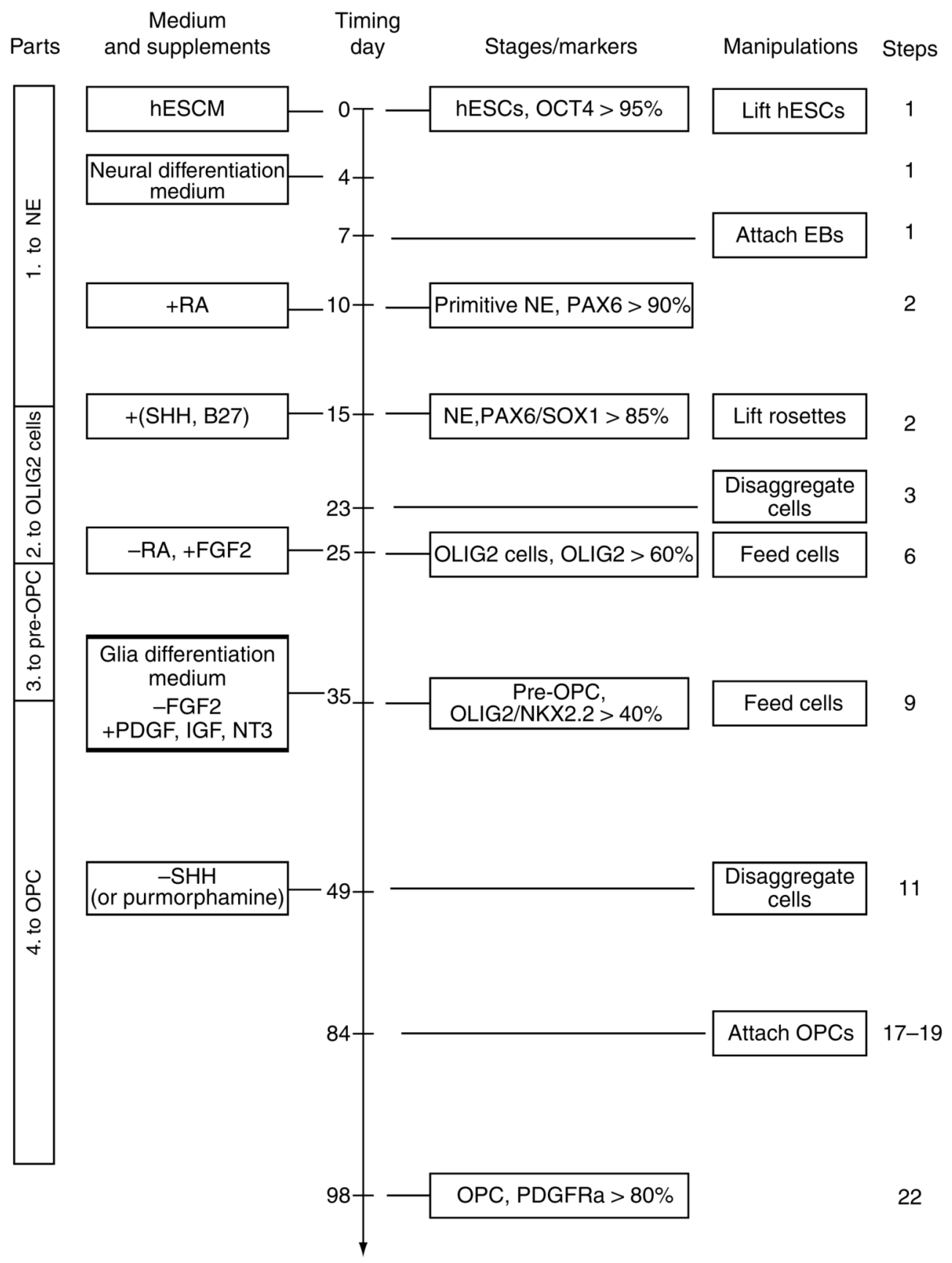

Figure 1.

Flowchart of the four-part oligodendrocyte progenitor cell (OPC) differentiation from human embryonic stem cells (hESCs). Part one differentiates the hESCs to PAX6+ neuroepithelial cells in the serum free medium without morphogens for 2 weeks. Part two patterns the neureopithelia to OLIG2+ ventral progenitors by retinoic acid (RA) and sonic hedgehog (SHH) (or purmorphamine). In part three, the neurogenic potential of the OLIG2 progenitors is repressed by removal of RA and addition of fibroblast growth factor 2 (FGF2) for $10 \mathrm{~d}$. The OLIG2 progenitors now co-express NKX2.2 and become gliogenic, which we refer to as preOPCs. Finally, the pre-OPCs are differentiated to OPCs in the glia differentiation medium, which lacks FGF2, and contains platelet-derived growth factor (PDGF), insulin like growth 
factor (IGF) and neurotrophin 3 (NT3). This fourth part takes 8-9 weeks. The OPCs express SOX10, platelet-derived growth factor receptor alpha (PDGFR $\alpha$ ), NG2 in addition to OLIG2 and NKX2.2. This chart is modified from Figure 1 of our motoneuron differentiation protocol $^{25}$. hESCM, human embryonic stem cell medium; IGF, insulin like growth factor; NE, neuroepithelial cells; PDGF, platelet derived growth factor; NT3, neurotrophin 3. Percentage denotes the promotion of positive cells among total progenies from the starting hESCs. 

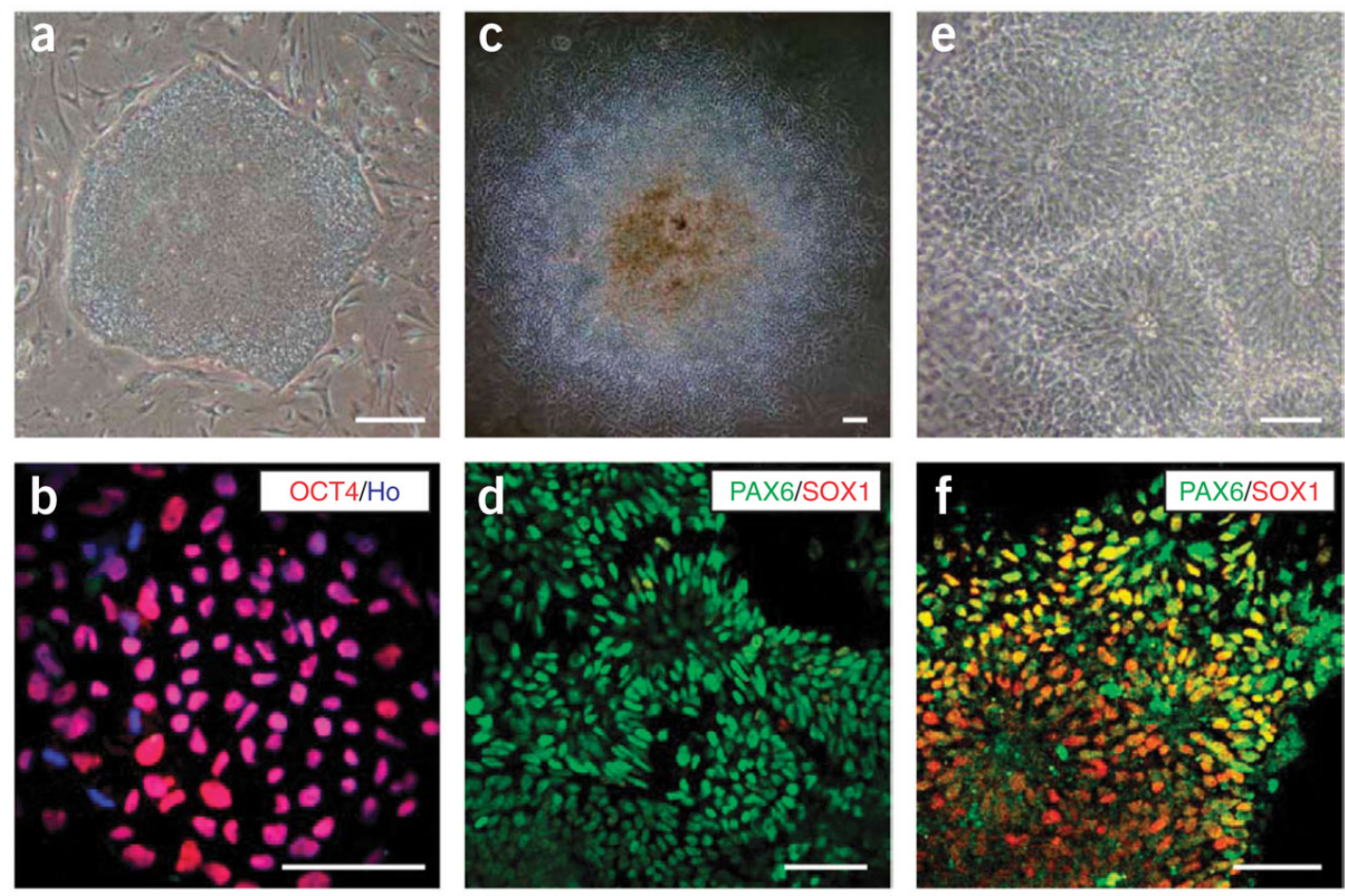

Figure 2.

Induction of neuroepithelial cells. Human embryonic stem cells (hESCs) growing on mouse embryonic fibroblast (MEF) feeder cells as a uniform colony (a). All cells are positively stained for OCT4 (b). On day 10, columnar epithelial cells appear and organize into rosettes in the colony (c). These cells express PAX6 but not SOX1 (d). At day 15, neural tube-like rosettes are obvious (e) and cells within these rosettes are stained for both PAX6 and SOX1 (f). Scale bar, $50 \mu \mathrm{m}$. Ho: Hoechst 33258. 

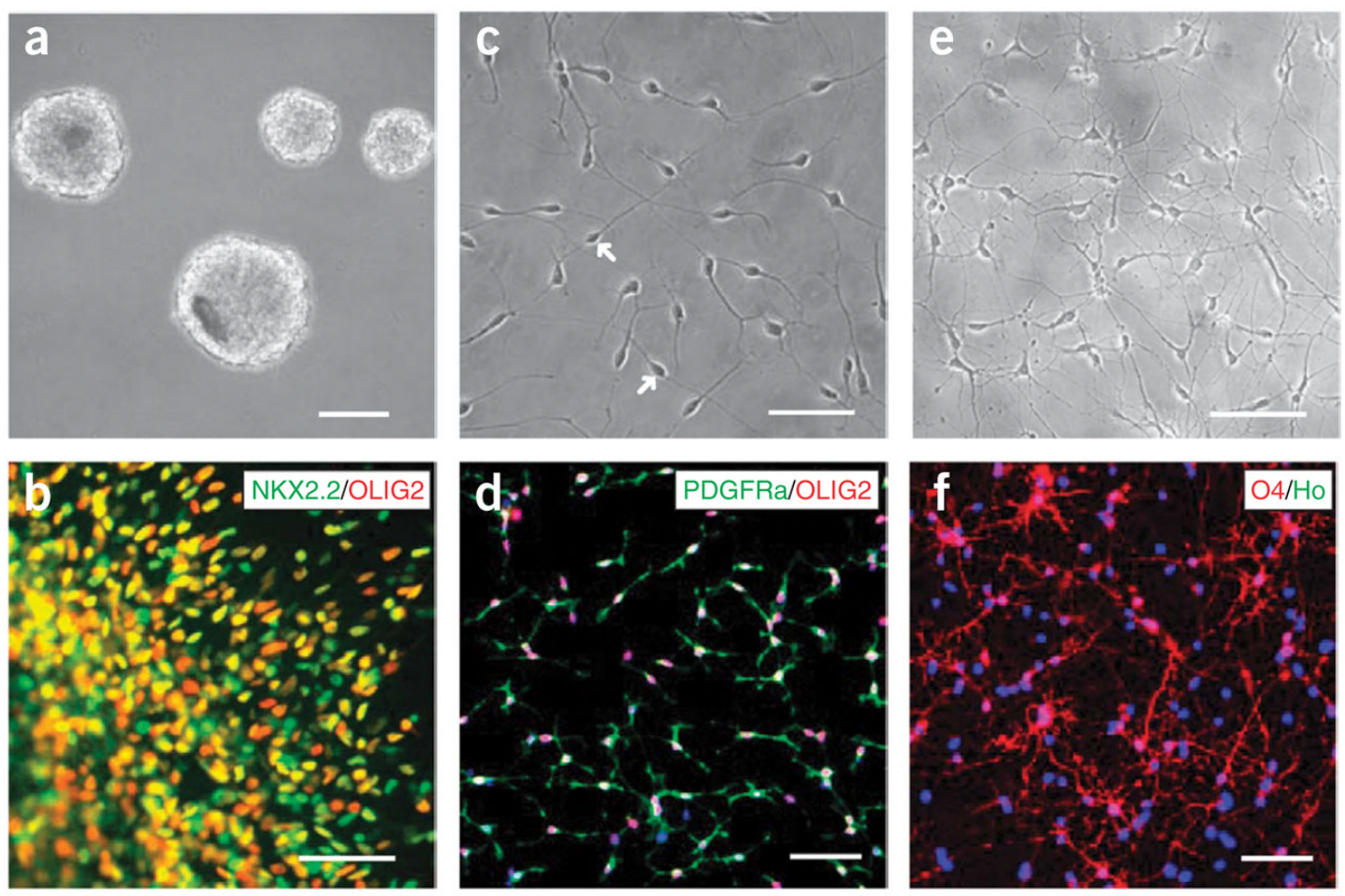

Figure 3.

Generation of pre-oligodendrocyte progenitor cells (OPCs) and OPCs. The pre-OPCs grow as spheres in suspension at day 35 (a) and express both OLIG2 and NKX2.2 (b). Dissociated OPCs after 14 weeks of human embryonic stem cell (hESC) differentiation exhibit a bipolar morphology (c, arrows), and co-express OLIG2 and platelet-derived growth factor receptor alpha (PDGFR $\alpha)(\mathbf{d})$. At 4 weeks after growing on substrate for differentiation, OPCs become multipolar immature oligodendrocytes (e), and many of these cells express 04 (f). Scale bar, $50 \mu \mathrm{m}$. Ho denotes Hoechst 33258. 
TABLE 1

Antibodies used for staining cells to verify their identity.

\begin{tabular}{lllll}
\hline Antibody & Isotype & Source & Cat. no. & Dilution \\
\hline OCT4 & Mouse IgG & Santa Cruz & sc-5279 & $1: 1000$ \\
PAX6 & Mouse IgG & DSHB & PAX6 & $1: 5000$ \\
SOX1 & Goat IgG & R\&D & AF3366 & $1: 1000$ \\
OLIG2 & Goat IgG & Santa Cruz & SC-19969 & $1: 500$ \\
NKX2.2 & Mouse IgG & DSHB & 74.5 A5 & $1: 50$ \\
NG2 & Mouse IgG & BD Pharmingen & 554275 & $1: 400$ \\
PDGFR ${ }^{*}$ & Rabbit IgG & Santa Cruz & SC-338 & $1: 400$ \\
04 & Mouse IgM & Chemicon & MAB3345 & $1: 50$ \\
\hline
\end{tabular}

PDGFR $\alpha$, platelet-derived growth factor receptor alpha. After fixation with $4 \%(\mathrm{wt} / \mathrm{vol})$ paraformaldehyde (PFA) for 10 min and penetrating with $0.1 \%$ ( $\mathrm{vol} / \mathrm{vol}$ ) Triton-X, the cells are incubated with serum (donkey or goat) for $1 \mathrm{~h}$ to block the unspecific staining and with primary antibodies overnight at $4{ }^{\circ} \mathrm{C}$, followed by thorough rinsing with phosphate-buffered saline (PBS) and incubation with fluorophore labeled secondary antibodies for $30 \mathrm{~min}$ at room temperature.

* The cells on coverslips are incubated with primary antibodies in L15 medium for 15-20 min at room temperature before fixation, and then stained with secondary antibodies. 
TABLE 2

Troubleshooting table.

\begin{tabular}{|c|c|c|c|}
\hline Step & Problem & Possible reason & Solution \\
\hline 18 & $50 \mu \mathrm{l}$ of medium does not stay on coverslips & $\begin{array}{l}\text { The coverslips do not recover to room } \\
\text { temperature and are still wet }\end{array}$ & $\begin{array}{l}\text { Leave the plates at room } \\
\text { temperature longer or leave the lid } \\
\text { half open for quick evaporation }\end{array}$ \\
\hline 19 & The coverslips dry out & $\begin{array}{l}\text { The drop of medium has drained off the } \\
\text { coverslip }\end{array}$ & $\begin{array}{l}\text { eWhen moving and transferring the } \\
\text { plate, make sure this is done gently. } \\
\text { Ensure that the incubator door is } \\
\text { opened and closed gently }\end{array}$ \\
\hline 22 & No PDGFR $\alpha$ stained & $\begin{array}{l}\text { The cells are overfixed or not fixed } \\
\text { properly }\end{array}$ & $\begin{array}{l}\text { Stain for the membrane protein } \\
\text { before fixation as described in the } \\
\text { notes of Table } 1\end{array}$ \\
\hline 23 & No $04+$ cells & $\begin{array}{l}04 \text { cells died and detached; or } \\
\text { inappropriate staining procedure }\end{array}$ & $\begin{array}{l}\text { Adding } 0.5 \% \text { (vol/vol) fetal bovine } \\
\text { serum into the culture medium may } \\
\text { help the survival of } 04+\text { cells. } \\
\text { Incubate the cells with } 04 \text { antibody } \\
\text { for } 15 \text { min before fixing the cells } \\
\text { with } 4 \% \text { PFA (wt/vol) }\end{array}$ \\
\hline
\end{tabular}

PDGFR $\alpha$, platelet-derived growth factor receptor alpha; PFA, paraformaldehyde. 